\title{
Pengaruh Kompensasi dan Lingkungan Kerja terhadap Kinerja Karyawan Pada PT Klasik Distribusi Indonesia
}

\author{
Jonathan Christopher Chandra dan Ronnie Resdianto Masman \\ Program Studi Manajemen Fakultas Ekonomi dan Bisnis \\ Universitas Tarumanagara, Jakarta \\ E-mail: jonathancchandra@gmail.com
}

\begin{abstract}
The purpose of this research is to find the effect of compensation and work environment to employee job performance of Klasik Distribusi Indonesia company. The population of this research were employee who have been working at Klasik Distribusi Company. There are 70 respondents in this research. The results of this research showed that there are significant influence between compensation and work environment to employee's job performance.
\end{abstract}

Keywords: Compensation, Work Environment, Employee's Job Performance

Abstrak: Tujuan dari penelitian ini adalah untuk mengetahui pengaruh kompensasi dan lingkungan kerja terhadap kinerja karyawan pada PT Klasik Distribusi Indonesia. Populasi pada penelitian ini adalah karyawan yang bekerja pada PT Klasik Distribusi Indonesia. Terdapat 70 responden dalam penelitian ini. Hasil dari penelitian ini menunjukkan bahwa ada pengaruh yang signifikan antara kompensasi dan lingkungan kerja terhadap kinerja karyawan.

Kata Kunci: Kompensasi, Lingkungan Kerja, Kinerja

\section{LATAR BELAKANG}

Sumber daya manusia memiliki peranan yang sangat penting bagi perusahaan. Bila tidak memiliki sumber daya manusia, kegiatan perusahaan tidak dapat berjalan. Sumber daya manusia berfungsi sebagai tenaga kerja yang mengelola dan menjalankan aktivitas pekerjaan yang ada di dalam perusahaan dan merupakan kewajibannya terhadap perusahaan. Untuk itu perusahaan harus mengetahui kebutuhan sumber daya manusia yang dimiliki agar karyawan yang bekerja pada perusahaan dapat mengeluarkan kinerja terbaiknya. Bila karyawan dapat mengeluarkan kinerja terbaik, tentunya perusahaan akan dapat dengan mudah mencapai tujuan dan sasaran perusahaan serta perusahaan dapat berkembang jadi lebih baik.

PT Klasik Distribusi Indonesia didirikan di Jakarta, Indonesia pada tahun 2013. PT Klasik Distibusi Indonesia merupakan perusahaan yang bergerak di bidang distribusi dan berfokus pada 5 jenis produk yaitu batik, home applicants, consumer goods, personal care, dan health \& gym equipment. Perusahaan sudah menjadi distribution channel ke berbagai ke berbagai perusahaan besar di Indonesia, seperti Sogo, Metro, AEON, Matahari, Seibu, Centro, Diamond Supermarket, Carrefour, Ramayana, Fabelio, Gramedia, Sephora, Shopee, Tokopedia, dan Lazada. Oleh karena itu PT Klasik Distribusi Indonesia harus mampu memperhatikan kinerja karyawannya dalam jumlah yang banyak dalam mencapai tujuan dan sasaran perusahaan. Tujuan dari penelitian ini yaitu: untuk mengetahui apakah kompensasi, dan lingkungan kerja karyawan berpengaruh terhadap kinerja karyawan.

\section{KAJIAN TEORI}

Menurut Santoso dan Masman (2016, h. 3) kompensasi adalah keseluruhan bentuk imbalan yang diberikan dalam bentuk finansial dan nampak, yang diterima oleh karyawan 
sebagai imbalan atas hubungan kerjanya dengan perusahaan. Menurut Milkovich (2014) kompensasi merupakan upah yang diterima oleh seorang individu sebagai imbalan dari pekerjaan yang mereka lakukan, yang secara umum merupakan sumber financial security mereka.

Menurut Sedarmayanti (2001, h. 1) lingkungan kerja adalah keseluruhan alat perkakas dan bahan yang dihadapi lingkungan sekitar di mana seseorang bekerja, metode kerjanya, serta pengaturan kerjanya baik sebagai individu maupun kelompok. Lingkungan kerja yang positif tentunya akan membuat karyawan betah dalam bekerja pada perusahaan. Lingkungan kerja memiliki pengaruh yang mendukung karyawan dalam menyelesaikan tugas dan tanggung jawabnya terhadap perusahaan. Melalui fasilitas yang disediakan dan hubungan antar sesama rekan kerja yang harmonis mampu membuat karyawan bertahan di dalam perusahaan dan melakukan pekerjaannya dengan baik.

Menurut Wibowo (2016, h. 8) Kinerja adalah tentang melakukan pekerjaan dan hasil yang dicapai dari pekerjaan tersebut, tentang apa yang dikerjakan dan bagaimana cara mengerjakannya. Menurut Mondy \& Martocchio (2016, h. 189) proses penilaian kinerja merupakan penilaian awal untuk mengindetifikasikan kinerja individu yang spesifik untuk mencapai tujuan yang diinginkan. Langkah selanjutnya dalam penilaian adalah dengan menetapkan kriteria kinerja dan mengomunikasikan ekspektasi kinerja kepada karyawan yang berkepentingan. Pekerjaan ini dilakukan oleh pengawas untuk menilai kinerja. Pada akhir periode penilaian, penilai akan meninjau kinerja kerja karyawan dan memberikan evaluasi mengenai standart yang diingkinkan oleh perusahaan.

Kerangka pemikiran dalam penelitian ini sebagai berikut:

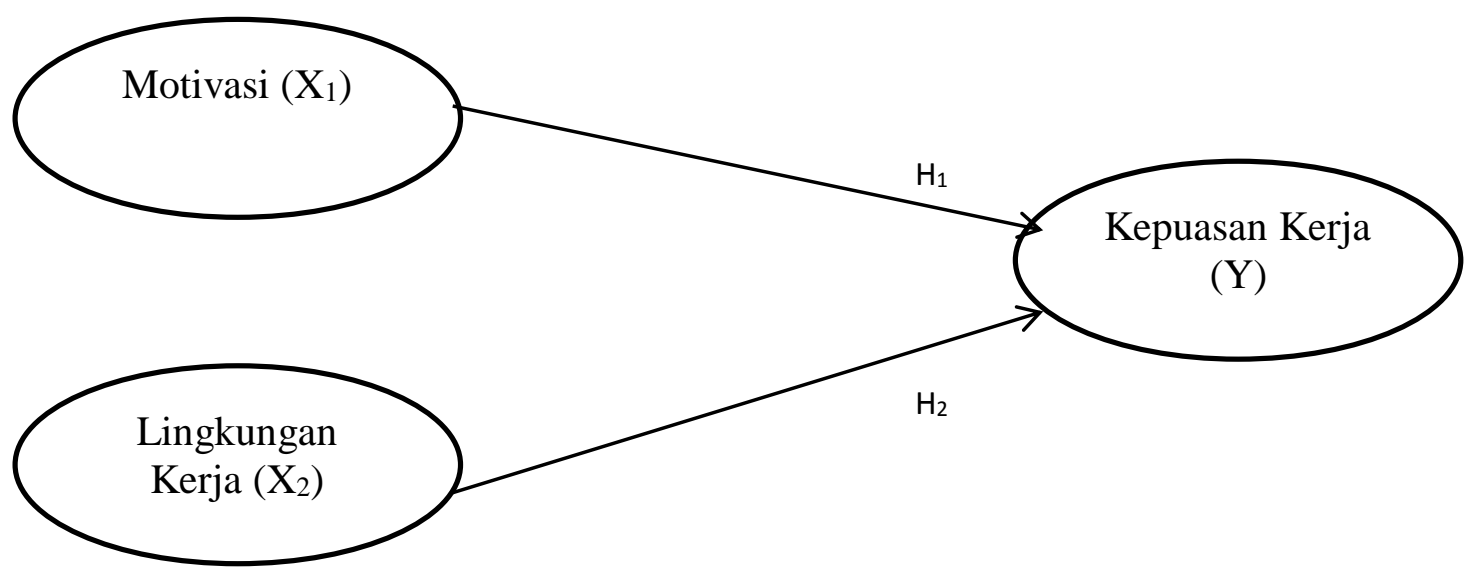

Gambar 1. Kerangka Pemikiran

\section{Hipotesis:}

Dengan demikian, berdasarkan kerangka pemikiran, hipotesis pada penelitian ini dirumuskan sebagai berikut:

H1: Kompensasi memiliki pengaruh yang positif terhadap kinerja karyawan pada PT. Klasik Distribusi Indonesia di Jakarta.

H2: Lingkungan kerja memiliki pengaruh yang positif terhadap kinerja karyawan PT. Klasik Distribusi Indonesia di Jakarta. 


\section{METODOLOGI}

Menurut Supranto (2012, h. 332), desain penelitian adalah aspek teknis yang berkenaan dengan mengumpulkan, mengolah, menyajikan, dan menganalisis data termasuk menguji hipotesis. Pada penelitian ini, peneliti menggunakan desain penelitian kausal. Penelitian kausal ini digunakan untuk menguji pengaruh keterkaitan antara variabel dependen dan variabel independen. Menurut Sugiyono (2013, h. 3) metode kausal adalah hubungan yang bersifat sebab akibat oleh variabel independen (mempengaruhi) terhadap variabel dependen (dipengaruhi). Dalam penelitian ini yang akan menjadi sampel adalah seluruh populasi karyawan pada PT Klasik Distribusi Indonesia dengan jumlah 70 orang karyawan. Teknik pengumpulan data dalam penelitian ini menggunakan kuesioner dan wawancara. Aplikasi yang digunakan peneliti dalam penelitian ini adalah SmartPLS versi 3.0. Uji statistik yang digunakan dalam SmartPLS versi 3.0 adalah sebagai berikut:

Uji Validitas, menggunakan convergent validity yaitu suatu indikator dikatakan valid apabila nilai outer loading di atas 0.5 (Ghozali, 2014). Convergent validity juga menilai AVE (Average Variance Extraced) apabila diatas 0.5 maka variabel dikatakan valid. Menurut Sugiyono (2013, h. 202) validitas merupakan derajat ketetapan antara data yang ada pada objek penelitian dengan daya yang dilaporkan oleh penelitian.

Uji Reliabilitas, menggunakan metode Alpha-Cronbach. Tingkat reabilitasnya diukur berdasarkan skala alpha 0 sampai dengan 1 . Kuesioner bersifat reliable apabila memiliki nilai alpha lebih besar dari 0.7. Menurut Sekaran dan Bougie (2016, p. 223), reliabilitas adalah keandalan untuk membuktikan alat ukur sesuai dengan stabilitas dan konsistensi. Selanjutnya, untuk hasil analisis data dapat dilakukan pengujian sebagai berikut:

1. Uji Koefisien Determinan (Uji R) yaitu pengujian yang dilakukan apabila $\mathrm{R}^{2}$ semakin besar atau mendekati 1, maka dapat disimpulkan model tersebut semakin tepat. Koefisien determinasi pada regresi linear biasa disebut sebagai seberapa besar kemampuan semua variabel bebas dalam menjelaskan varians dari variabel terikat.

2. Uji Hipotesis yaitu Variabel independen menunjukkan tingkat signifikan apabila nilai $\mathrm{t}$ value $\geq 1,96$ pada tingkat alpha $5 \%$. Uji hipotesis juga terkadang disebut dengan konfirmasi analisis data.

3. Uji Goodness of Fit adalah pengujian hipotesis kompatibilitas (goodness of fit) merupakan pengujian hipotesis untuk menentukan apakah suatu himpunan frekuensi yang diharapkan sama dengan frekuensi yang diperoleh dari suatu distribusi, seperti distribusi binomial, normal, atau dari perbandingan lain. Pengujian ini digunakan untuk mengvalidasi performa gabungan antara outer model dan inner model yang memiliki range nilai antara 0-1 dengan interpretasi 0-0,25 (Gof Kecil), 0,25-0,36 (Gof Moderat), dan >36 (Gof Besar).

\section{HASIL UJI STATISTIK}




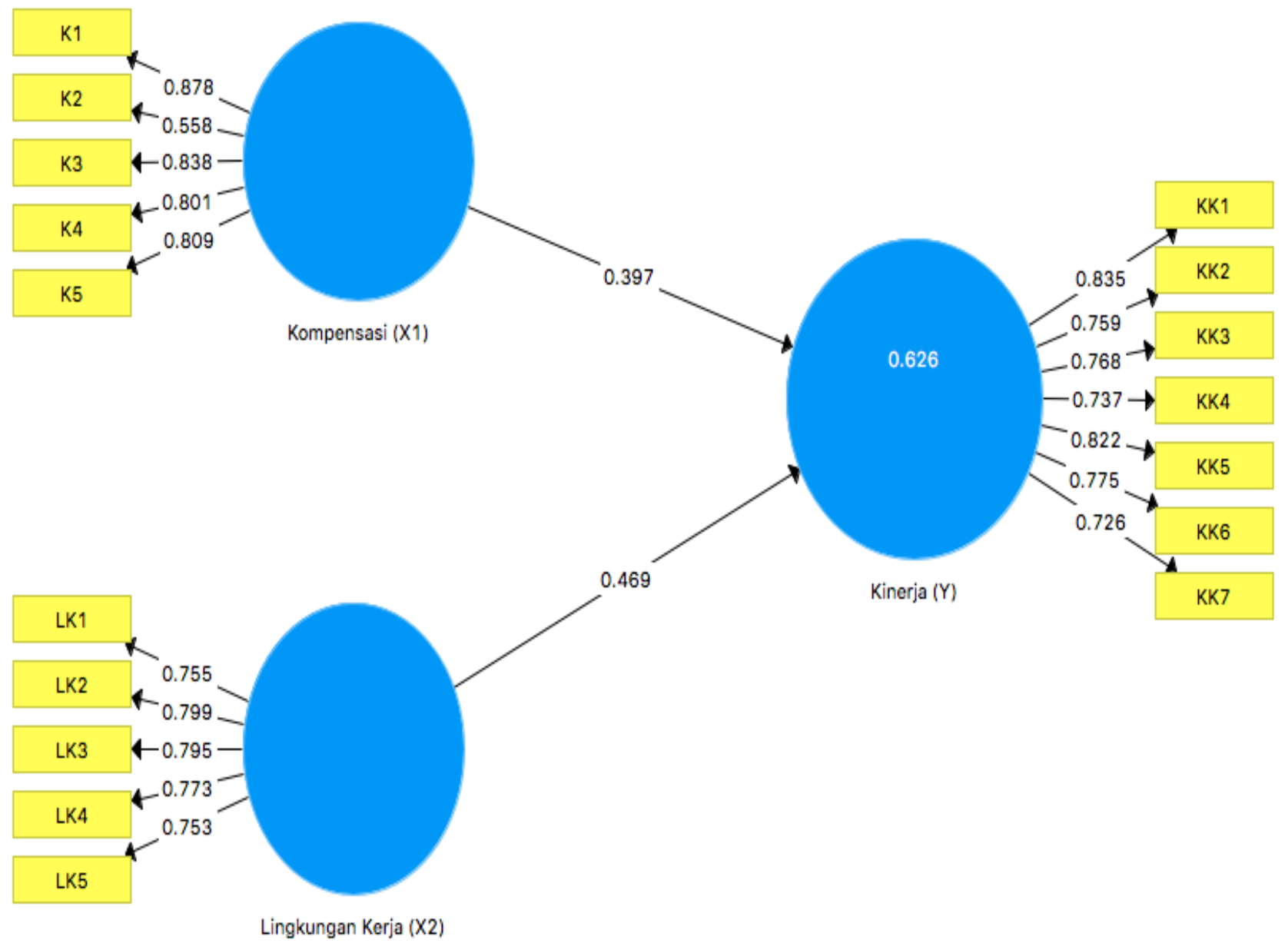

Gambar 2. Hasil Output SmartPLS 


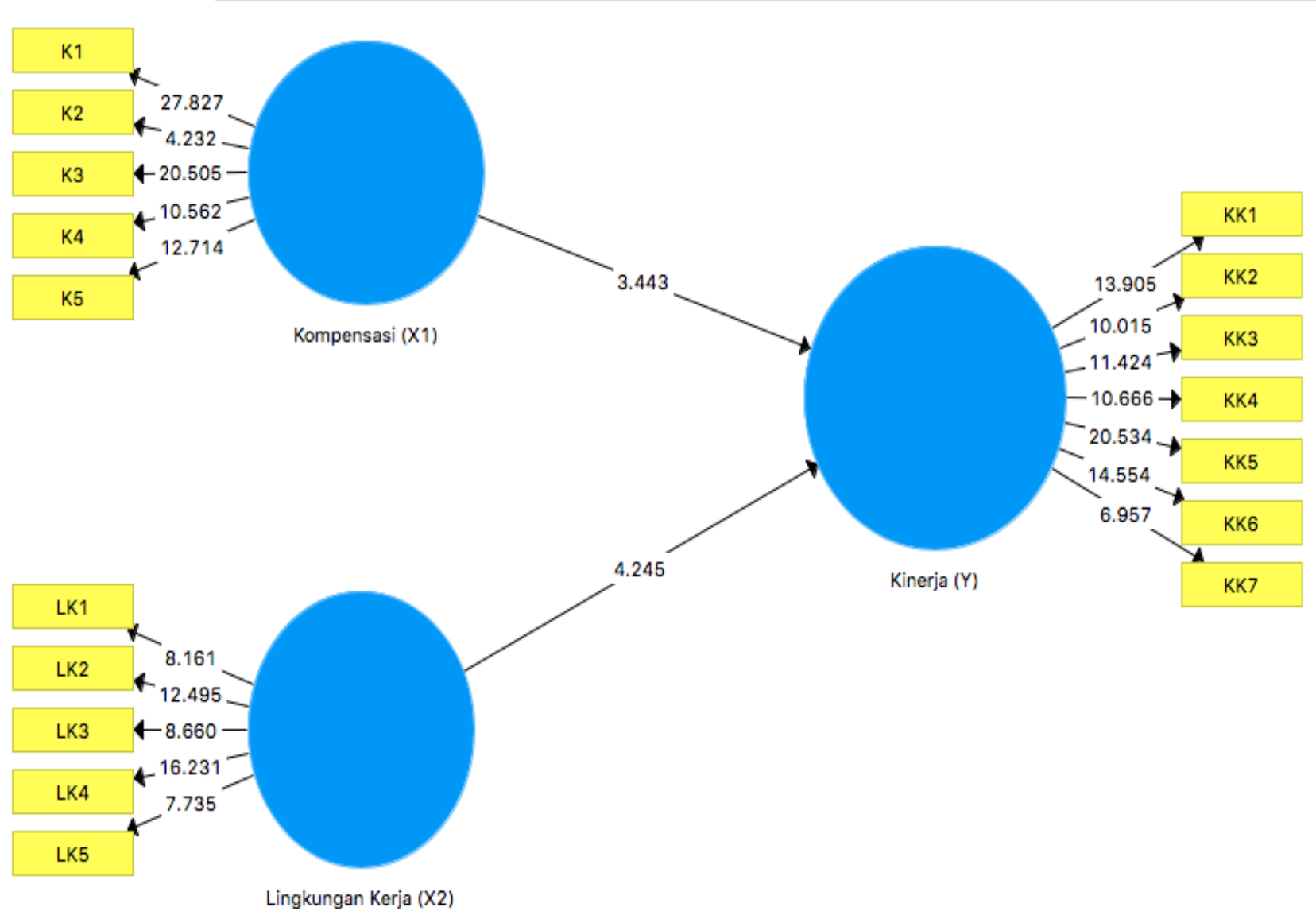

\section{Gambar 3. Hasil Uji Bootsrapping}

Dari 70 responden, 38 responden adalah wanita dan sisanya pria. Sebagian besar responden berusia 21 tahun sampai 30 tahun (36 orang, 51.4\%) dan sisanya berusia 31 tahun sampai 40 tahun (28 orang, 40\%), dan 41 tahun sampai 50 tahun (6 orang, 8.6\%). Pendidikan terakhir sebagian responden adalah S1 (45 orang, 64.3\%) dan sisanya SMA/SMK (13 orang, $18.6 \%$ ), S2 (8 orang, 11.4\%), dan Diploma (4 orang,5.7\%). Durasi lama bekerja sebagian besar responden adalah kurang dari 1 sampai 5 tahun (40 orang, 57.1\%) dan sisanya $<1$ tahun (17 orang, 24.3\%), dan antara 5 tahun sampai 7 tahun (13 orang, 18.6\%).

Penulis akan membahas tentang hasil pengolahan data dengan software SmartPLS berdasarkan gambar di atas:

Pada variabel kompensasi (X1), hasil tertinggi diperoleh pada indikator pertama yaitu "insentif yang saya terima diberikan secara wajar" dengan hasil sebesar 0.878 , sementara untuk hasil terendah diperoleh indikator kedua yaitu "saya menerima gaji tepat waktu" dengan hasil sebesar 0.558. Pada variabel lingkungan kerja (X2), hasil tertinggi diperoleh pada indikator kedua yaitu "saya memiliki hubungan yang baik dengan rekan kerja saya" dengan hasil sebesar 0.799 sementara hasil terendah diperoleh pada indikator kelima yaitu "saya puas dengan kesempatan pelatihan pengembangan yang diberikan oleh perusahaan" dengan hasil sebesar 0.753. Pada variabel kinerja (Y), hasil tertinggi diperoleh pada indikator pertama yaitu "saya memiliki tanggung jawab dalam bekerja" dengan hasil sebesar 0.835 sementara hasil terendah diperoleh pada indikator ketujuh yaitu "saya memiliki komunikasi yang baik antara atasan dan bawahan sehingga dapat meningkatkan kinerja" dengan hasil sebesar 0.726 . 
Tabel 1. Hasil Uji Validitas

\begin{tabular}{|c|c|}
\hline Kompensasi (X1) & 0.616 \\
\hline Lingkungan Kerja (X2) & 0.601 \\
\hline Kinerja (Y) & 0.602 \\
\hline
\end{tabular}

Nilai AVE dari setiap variabel adalah lebih besar dari 0.5 sehingga dapat ditarik kesimpulan bahwa semua variabel telah memiliki discriminant validity yang baik.

Tabel 2. Uji Reliabilitas

\begin{tabular}{|c|c|}
\hline & Cronbach' Alpha \\
\hline Kompensasi (X1) & 0.838 \\
\hline Lingkungan Kerja (X2) & 0.836 \\
\hline Kepuasan Kerja (Y) & 0.889 \\
\hline
\end{tabular}

Nilai cronbach-alpha untuk tiap variabel adalah lebih besar dari 0,7 sehingga dapat di simpulkan bahwa pernyataan untuk setiap variabel adalah reliable.

Tabel 3. Hasil Uji Koefisien Determinan (Uji R)

\begin{tabular}{|c|c|c|}
\hline & $R$ Square & $R$ Square Adjusted \\
\hline Kinerja (Y) & 0.626 & 0.615 \\
\hline
\end{tabular}

Berdasarkan hasil Adjusted $R$ Square $\left(\mathrm{R}^{2}\right)$ pada tabel diatas adalah 0.615 , artinya di mana proporsi kompensasi dan lingkungan kerja sebesar $61.5 \%$ dan sisanya sebesar $38.5 \%$ dijelaskan pada variabel kinerja. Sedangkan hubungan kinerja terhadap kompensasi dan lingkungan kerja berdasarkan hasil nilai $R$ Square adalah 0.626 yaitu positive dan signifikan bahwa ada hubungan kinerja terhadap kompensasi dan lingkungan kerja.

Tabel 4. Hasil Uji Hipotesis

\begin{tabular}{|c|c|c|c|c|c|}
\hline & $\begin{array}{c}\text { Original } \\
\text { Sample (O) }\end{array}$ & $\begin{array}{c}\text { Sample } \\
\text { Mean } \\
(M)\end{array}$ & $\begin{array}{c}\text { Standard } \\
\text { Deviation }\end{array}$ & $\begin{array}{c}T \\
\text { Statistics }\end{array}$ & P Values \\
\hline $\begin{array}{c}\text { Kompensasi (X1) -> } \\
\text { Kinerja (Y) }\end{array}$ & 0.397 & 0.397 & 0.115 & 3.443 & 0.001 \\
\hline $\begin{array}{c}\text { Lingkungan Kerja (X2) -> } \\
\text { Kinerja (Y) }\end{array}$ & 0.469 & 0.482 & 0.110 & 4.245 & 0.000 \\
\hline
\end{tabular}

Dari hasil pengujian variabel kompensasi terhadap kepuasan kerja karyawan memiliki koefisien jalur 0.397 dan T-Value sebesar 3.443 dimana T-Value lebih besar dari 1.96. Oleh karena itu dapat disimpulkan kompensasi memiliki pengaruh signifikan terhadap kinerja karyawan PT Klasik Distribusi Indonesia.

Dari hasil pengujian variabel lingkungan kerja terhadap kepuasan kerja karyawan memiliki koefisien jalur 0.469 dan T-Value sebesar 4.245 dimana T-Value lebih besar dari 1.96. Oleh karena itu dapat disimpulkan lingkungan kerja memiliki pengaruh signifikan terhadap kinerja karyawan PT Klasik Distribusi Indonesia. 
Tabel 6. Hasil Uji Goodness of Fit

\begin{tabular}{|c|c|}
\hline & Saturated Model \\
\hline NFI & 0.702 \\
\hline
\end{tabular}

Nilai ini berkisar dari 0-1, nilai NFI yang mendekati 1 menunjukan bahwa model yang diuji memiliki ketepatan yang baik .

\section{Kesimpulan}

Pada variabel kompensasi dan lingkungan kerja memiliki pengaruh positif dan signifikan terhadap kepuasan kinerja karyawan pada PT Klasik Distribusi Indonesia di Jakarta.

\section{Penutup}

Berdasarkan dari hasil penelitian yang telah dilakukan, peneliti akan memberikan beberapa saran atau masukan yang sekiranya dapat digunakan atau bermanfaat bagi perusahaan maupun kepada penelitian selanjutnya, sebagai berikut:

1. Untuk PT Klasik Distribusi Indonesia, Sebaiknya perusahaan tetap terus mempertahankan kinerja terbaik karyawannya agar dapat mencapai tujuan dan sasaran yang sudah pernah di terapkan sebelumnya. Kinerja karyawan dapat dipertahankan dengan cara memberikan lingkungan kerja yang positif kepada mereka agar mereka terus dapat semangat dalam bekerja. Perusahaan juga diharapkan dapat tetap mempertahankan program insentif yang sesuai dengan jabatan dan pekerjaan karyawan.

2. Untuk peneliti selanjutnya, diharapkan untuk menambah jumlah sampel dan variabel penelitian, karena semakin banyak sampel yang ada maka data yang dihasilkan akan lebih bervariasi. Serta menyiapkan indikator yang tepat sesuai dengan kondisi perusahaan agar mendapatkan hasil yang diinginkan. Diharapkan juga untuk peneliti selanjutnya agar menggunakan data kinerja yang merupakan hasil penilaian dari atasan agar tidak terjadi bias dalam menilai kinerja karyawan.

\section{DAFTAR PUSTAKA}

Do, Tung. Thanh. 2018. "How spirituality, climate and compensation affect job performance." Social Responsibility Journal. Volume 14 no 2. pp 396-409.

Ghozali, Imam. 2014. Structural Equation Modeling, Metode Alternatif dengan Partial Least Square (PLS). Edisi 4. Semarang: Badan Penerbit Universitas Diponegoro.

Kasenda, Ririvega. 2013. "Kompensasi dan Motivasi Pengauhnya Terhadap Kinerja Karyawan pada PT Bangun Wenang Beverages Company Manado". Jurnal EMBA, Volume 1 No 3, Juni 2013. 853-859.

Lantara, I. M. R. B., \& Utama, I. W. M. (2015). Pengaruh Insentif Finansial, Insentif Non Finansial dan Lingkungan Kerja Terhadap Kepuasan Kerja Karyawan pada PT. Tiara Cipta Nirwana. E-Jurnal Manajemen, Volume 3 no 4.

Lin, S., Lamond, D., Yang, C. L., \& Hwang, M. 2014. "Personality traits and simultaneous reciprocal influences between job performance and job satisfaction". Chinese Management Studies. Volume 8 No 1. Hlm 6-26.

Milkovich, G.T., Newman, J.M. \& Gerhart. B. (2014). Compensation. McGraw- Hill/Irwin, New York, USA 
Mondy. W. R and Martocchio. J. J. 2016. Human Resource Management, 14th Edition. Pearson Education Limited: United States Of America

Ogbu, E.F., 2017. "The Effect of Compensation on Employee Performance In Nigeria Civil Service: A Study of Rivers Stat Board of Internal Revenue Service”. Journal of Strategic Human Resource Management, Volume 6 Issue 2, June 2017.

Palvalin, M. 2017. "How to measure impacts of work environment changes on knowledge work productivity-validation and improvement of the SmartWoW tool". Measuring Business Excellence, Volume 21 no 2.

Pawirosumarto, S., Sarjana, P. K., \& Gunawan, R. 2017. "The effect of work environment, leadership style, and organizational culture towards job satisfaction and its implication towards employee performance in Parador Hotels and Resorts, Indonesia". International Journal of Law and Management, Volume 59 No 6.

Santoso, Yussy dan Ronnie Masman. 2016. Executive Compensation Management. Jakarta: Kelompok Gramedia.

Sedarmayanti. 2001. Sumber Daya Manusia dan Produktivitas Kerja. Bandung: Mandar Maju.

Sekaran, U., \& Bougie, R. (2016). Research Methods for Business. Ed 7th. United Kingdom: Wiley.

Sugiyono. 2013. Metode Penelitian Pendidikan Kuantitatif, Kualitatif, dan R\&D. Bandung: Alfabeta.

Suharyanto, S., Nugraha, E., \& Permana, H. 2014. "Pengaruh Kompensasi dan Lingkungan Kerja Terhadap Kinerja Karyawan Divisi QIP PT. GSI Cianjur”. Jurnal Ilmiah Teknik Industri, Volume 13 No 2, 187-200.

Supranto, J. 2012. Metode Riset: Aplikasinya dalam Pemasaran. Jakarta: Penerbit Rineka Cipta.

Wibowo. (2016). Manajemen Kinerja. edisi 5. Rajawali Pers: Raja Grafindo Persada.

Widya, 2018. "Faktor Yang Mempengaruhi Kinerja Karyawan PT. ESA Di Jakarta Barat". Jurnal Muara Ilmu Sosial, Humaniora, dan Seni, Volume 2 No 2, Oktober 2018: hlm 544-550.

Yanuar, Yenny, Ronnie, 2019. “ Job Performance and Government Banks : Evidence from Indonesia”. International Journal of Innovation, Creativity and Change, Volume 6 No 11: hlm 197-212. 